\title{
Utilization of Water Produced Hydrogen for Domestic Heating Purposes
}

\author{
T. Tabazah ${ }^{\text {a }}$ M. A. Hamdan ${ }^{\text {a,** }}$, O. Abo Deyab ${ }^{\text {b }}$ and E. Abdelhafez ${ }^{a}$ \\ ${ }^{a}$ Department of Mechanical Engineering, Al-Zaytoonah University of Jordan, Amman, 11733 \\ ${ }^{b}$ Department of Mechanical Engineering, University of Jordan, Amman, Jordan, 11942
}

\begin{abstract}
In this work an electrolyzer is used to produce Brown gas (HHO) from water by supplying a DC electrical power to it. , the produced HHO was fed directly into the diesel line before being introduced into a domestic boiler. The effect of the added amounts of HHO to the diesel fuel on both the performance of the boiler and on the amount of emitted pollutants during the combustion process was investigated. It was found that the combustion efficiency of the boiler is improved with the amount of the HHO added, also it was found that the emitted pollutants was noticeably reduced with the added amounts of HHO.
\end{abstract}

Keywords: Brown gas, Hydrogen, Domestic heating, Water electrolysis

\section{Introduction}

The continuous volatility of petroleum price, the gradual decrease in the reserves of conventional energy resources, and the environmental problems created by the combustion of carbon based fuels, have placed great pressure on energy supplies to find solutions that cuts the energy bill, reduce the environmental impact of burning fossil fuel and improve the burning efficiency of the current combustion systems.

There are several possible solutions to alleviate the problems of using fossil fuels. This work discusses one method of improving fossil fuel combustion that can be implemented without large investment. This method involves burning hydrogen gas along with hydrocarbon fuels in combustion systems.

One way of producing hydrogen is through electrolysis of water and uses it in the form of hydrogen-oxygen (HHO) mixture. Water electrolysis is the process of passing an electric current through water breaking the bonds of the water molecule to produce hydrogen and oxygen gases called Brown's Gas or HHO gas, These studies were initiated by Yull Brown [1] in 1977 via equipment generally referred to as electrolyzes and the resulting gas is known as Brow gas.

* Corresponding author. Tel.: +00962777498980

Fax: + 96264291432; E-mail: engineering@ zuj.edu.jo

(c) 2014 International Association for Sharing Knowledge and Sustainability

DOI: $10.5383 /$ ijtee.07.02.006
The flame of Brown's Gas doesn't burst, and soot less, because no carbon comes out from Browns Gas. Therefore, Brown's Gas is being used as an unexceptional flame for every thermal processing industry including gas welding. Especially, brazing, soldering, gold and silver jewelry process, glass process, acryl process, miniature model making, minute process for electrical parts.

The main objective of this research is: To mix water produced Brown gas (HHO) with diesel fuel then the blend is burnt in domestic boiler for heating proposes. There are many reasons for applying hydrogen as an additional fuel to diesel fuel. Firstly, it increases the H/C ratio of the entire fuel. Secondly, injecting small amounts of Hydrogen to a diesel fuel could decrease heterogeneity of a diesel fuel spray due to the high diffusivity of Hydrogen, which makes the combustible mixture better premixed with air and more uniform. It could also reduce the combustion duration due to Hydrogen's high speed of flame propagation in relation to other fuels. In general the advantages of this work are:

1. Economic advantages: the results show that adding $\mathrm{HHO}$ gas to a boiler increases the boiler efficiency and reduces fuel consumption.

2. Environmental advantages: adding $\mathrm{HHO}$ gas to the boiler reduces harmful and greenhouse gases concentration in the exhaust. 


\section{Hydrogen fuel}

Hydrogen is a renewable source of energy as it's generated from water which is widely available as it covers over $70 \%$ of the surface of the earth. It is also a clean source of energy as the combustion of hydrogen generates steam which is clean and doesn't have a negative effect on the environment compared with liquid fuels. Hydrogen also happens to be the most abundant element in our universe; researchers just need to find ways to harness this energy in feasible ways. It is worth noting that Hydrogen gas has no color, smell or taste. It is also a non-corrosive gas and is not toxic to humans. It has the second widest flammability range in air of any gas; however, it is safe to use as leaking hydrogen rises and diffuses to a nonflammable mixture quickly.
Hydrogen has a high specific energy and very low density entailing high storage volume unless it is compressed (typically $70 \mathrm{MPa}$ ) or combined chemically with a metal alloy. To store hydrogen on-board in forms of a compressed gas, a cryogenic liquid or a gas dissolved in metal hydrides, a large amount of hydrogen is required to be stored and carried which leads to an increase in the overall weight of the vehicle [2]. Alternatively, in terms of liquid hydrogen storage, not only is the cost of onboard cryogenic containers high, but also a high level of energy is required to convert the gaseous hydrogen into liquid [3].

\section{Experimental Work}

The experimental setup used in this work is indicated in figure (1). As shown the following main equipments are used to conduct this work:

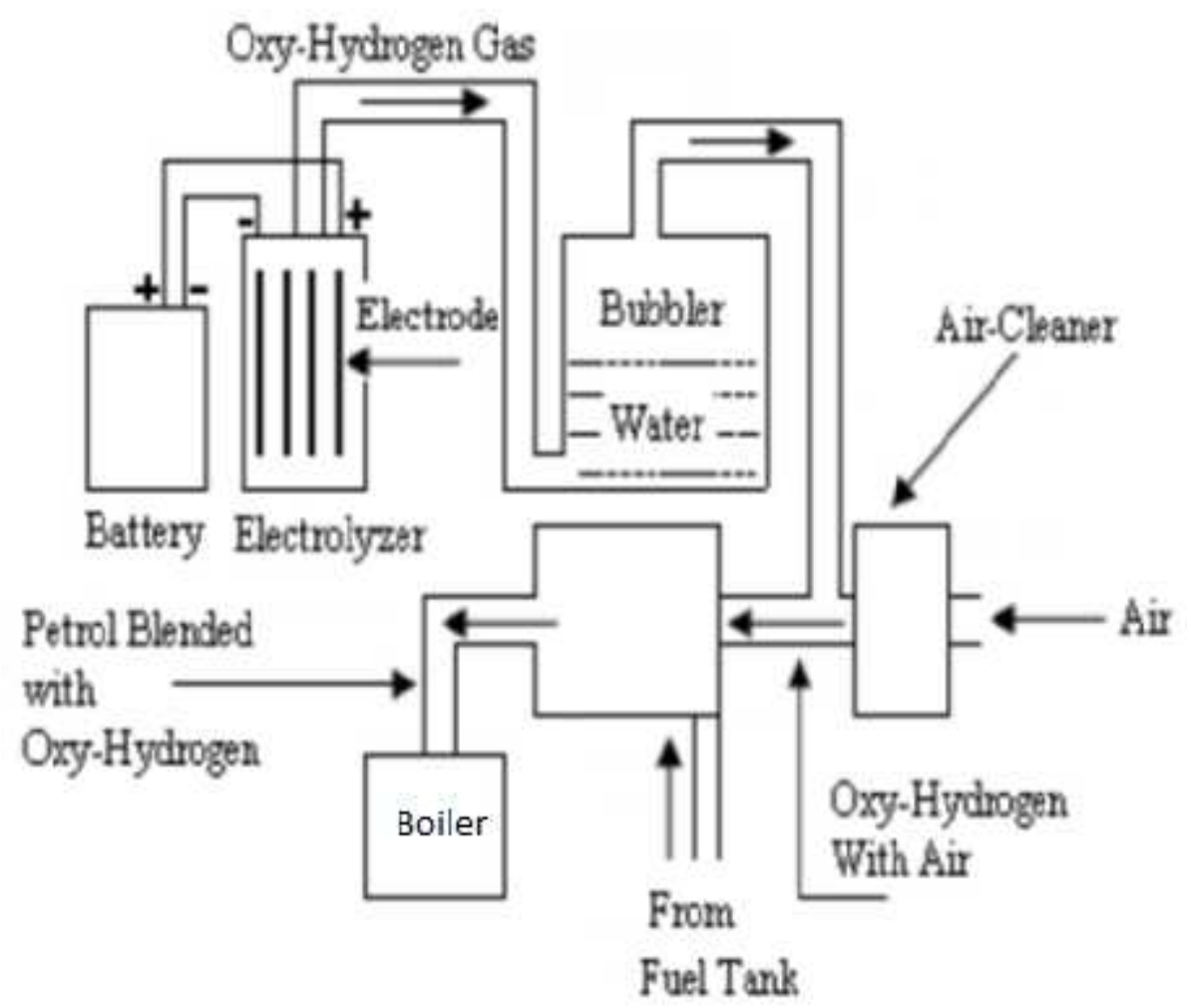

Fig. 1. Experiment setup

\subsection{Elctrolyzer}

The HHO gas was generated by a water electrolyzer and in order to simplify the setup, the HHO gas was generated using $12 \mathrm{~V}$ produced from the battery. The electrolysis of water produces hydrogen gas at the cathode and oxygen gas at the anode the generated mixture is then mixed with Diesel before it is introduced into the burner of the boiler.

\subsection{Fire trap (bubbler)}

A very important safety component is the fire trap "bubbler". It consists of a container filled with water. The bubbler works to prevent backfire from the system to the HHO source part by the shelled of water that work to separate these part from each other. It works by letting the gas coming in at the bottom and bubbling up through the water then collecting them above the water surface and is then drawn into the boiler burner. A check valve has been used to prevent the water from coming back to the hydrogen source during shut down of the system (when it cools down) these safety bubblers are filled with about $50 \%$ of water.

\subsection{Boiler}

Boiler brand Biasi was used with Bentone burner model (bentoflex ST120KA - 0.85 GPH) run by diesel oil. This boiler made of GG20 cast-iron construction for superior heat retention and durability and has a three-pass heat exchanger boiler design.

\subsection{Measurements Devices}

The following measuring devices were used: 


\subsubsection{Mass flow meter}

Dwyer company mass flow meter, of model GFM-2142 (serial no. 313124-1) with a full range of 100 LPM; has been used to find the mass flow of gases. This model combines a straight tube sensor with a restrictor flow element to provide high accuracy and repeatability. Flow rates are virtually unaffected by temperature and pressure variations. The total uncertainty of the reading according to Aalborg Instruments Lab may be in the range of $\pm 3 \%$ of full scale.

\subsubsection{Variable Area Glass Flow meter:}

A Dwyer VA Series Glass flow meter has been used for flow measurement. This type is suitable for metering carrier gases, liquid and gas measurement in pilot plants, laboratories, process flow and level indicating. Units are equipped with a standard 6-turn needle valve for flow rate control. And the total uncertainty of the reading may be in the range of $\pm 2 \%$ of full scale.

\subsubsection{Air velocity measurements:}

This Device manufactured by Dwyer instruments model UHH which has been used to measure the velocity \& temperature of air; Using a Thermo anemometer air velocity probe.

\subsubsection{Thermocouples:}

A thermocouple consists of two conductors of different materials (usually metal alloys) that produce a voltage in near the point where the two conductors are in contact. It is used to convert a temperature gradient into an electric signal. The various temperatures were measured using a thermocouple calibrator, and thermocouples used were Type $\mathrm{T}$ thermocouples. The thermocouples have been used to measure water temperature and to control the boiler burner.

\subsubsection{Exhaust gas analyzer}

The exhaust emission such as $\mathrm{CO} 2, \mathrm{NO}, \mathrm{NOx}$ and $\mathrm{O} 2$ were measured using a Nova Iplus gas analyzer. This analyzer was produced by MRU GmbH Company in Germany that specializes in developing, producing and marketing high quality emission monitoring analyzers. The unit is equipped with sensors to measure: NOx, NOx, SOx, COx, hydrocarbons, soot, and oxygen.

\section{Experimental Procedure}

Once the electrolyzer is set into operation, the produced Brown gas is fed iton the diesel fuel line to form the fuels mixture, which is introduced into the burner. The following main steps were followed during the work:

- The boiler was commissioned with diesel fuel only in order to obtain a reference point for the analysis to be conducted.

- The boiler was permitted to operate continuously for twenty (20) minutes to allow the variables of combustion, emissions...etc. to stabilize and reach the steady state of this operating circumstance.

- The installed Dewyer diesel flow meter reading is recorded indicating the actual flow rate of the diesel fuel.

- The HHO flow rate was also measured using the flow meter
- Readings

$$
\text { representing }
$$

exhaust

temperature $\mathrm{T}_{\text {exhaust }}$, exhaust gases of $\mathrm{CO}, \mathrm{CO} 2, \mathrm{SO} 2$ and $\mathrm{NOx}$ and boiler efficiency were read via the NOVA PLUS Gas Analyzer.

- At the end of the previous steps, data representing the diesel-operated-boiler has been collected; which indicates the reference to which the diesel-hydrogenoperated-boiler performance is to be compared.

- HHO gas is allowed to flow through the diesel suction pipe supplying the boiler with a mixture of $\mathrm{HHO}$ and diesel as fuel, for safety purposes,

- The HHO-diesel fuels mixed with air in the combustion chamber. and the previous steps of measuring flow rate of fuel, flow rate of water, exhaust gases and efficiency readings were recorded.

- Then, several flow rates of hydrogen were used to inspect the effect of this parameter on the boiler efficiency and environmental related emissions. 1 L/min [LPM], 2 LPM, and 3 LPM hydrogen flow rates were inspected; with the $1 \mathrm{LPM}$ considered to be the baseline for a functional supplemental hydrogen source.

\section{Experimental Results and Discussion}

The effect of adding HHO fuel to the diesel fuel on the performance and emission characteristics of a diesel boiler was studied. The obtained results relating to this study are discussed here

\subsection{Effect of adding HHO on the efficiencies}

The variations of combustion efficiencies resulting by the amounts of HHO mixture are presented in Figure (2). One can observe from this figure (8) that by increasing the induction of HHO mixture, thermal efficiency of the boiler increases due to the reduction of diesel flow rates occurring at same energy out ( temperature of water was set fixed at $80 \mathrm{C}^{\circ}$ to achieve constant boiler operating condition).

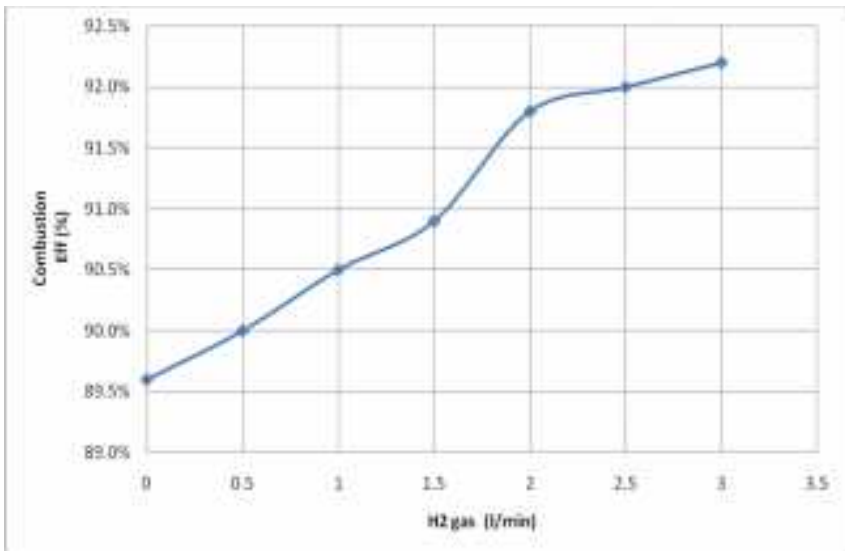

Fig. 2. Variation of Combustion efficiency with HHO flow rate.

For all of the studied cases, diesel boiler produced less thermal efficiency compared with diesel - HHO mixtures. This is due to the fact that the fuel consumption of diesel was lower compared with additional HHO gas mix with diesel, as shown in figure 3 . 


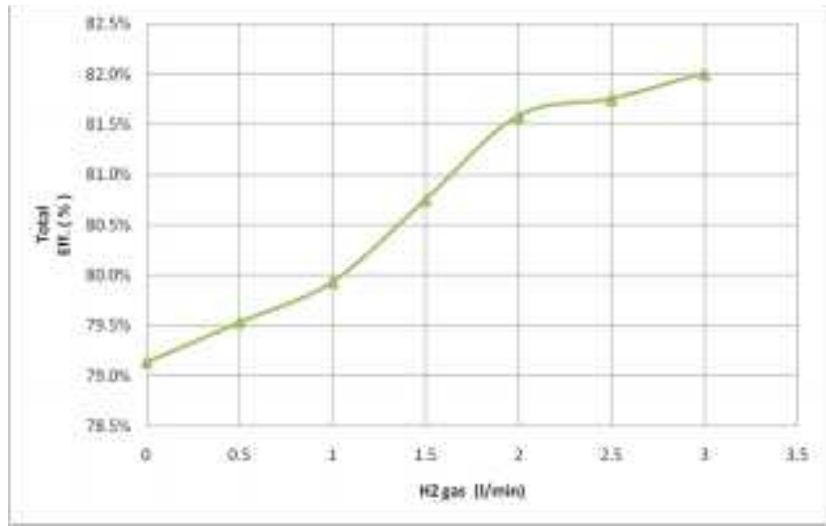

Fig. 3. Variation of thermal efficiency with HHO flow rate.

As indicated, upon increasing the flow rate of $\mathrm{HHO}$ gas, it is noted that thermal efficiency increases, this could be due to the fact that hydrogen combustion is faster; and accordingly has more efficient combustion that of individual diesel combustion. Furthermore, the flame speed of hydrogen is nine times faster than that for the diesel. Therefore, burning diesel in the presence of hydrogen results in an overall faster and more complete combustion.

\subsection{Effect on the exhaust Emissions:}

\subsubsection{Emission of Nitrogen oxides (NOx):}

Figure (4) shows the effect of hydrogen addition on NOx emission, NOx concentrations decrease; this is due to the lower peak temperature and pressure in addition to the reduction in the time required for dissociating $\mathrm{NO}$ to $\mathrm{N} 2$ and $\mathrm{O} 2$. This reaction is governed by the Zeldovich Mechanism. The three principal reactions (the extended Zeldovich mechanism) producing thermal NOx are:

$$
\begin{aligned}
& \mathrm{N}_{2}+\mathrm{O} \rightarrow \mathrm{NO}+\mathrm{N} \\
& \mathrm{N}+\mathrm{O}_{2} \rightarrow \mathrm{NO}+\mathrm{O} \\
& \mathrm{N}+\mathrm{OH} \rightarrow \mathrm{NO}+\mathrm{H}
\end{aligned}
$$

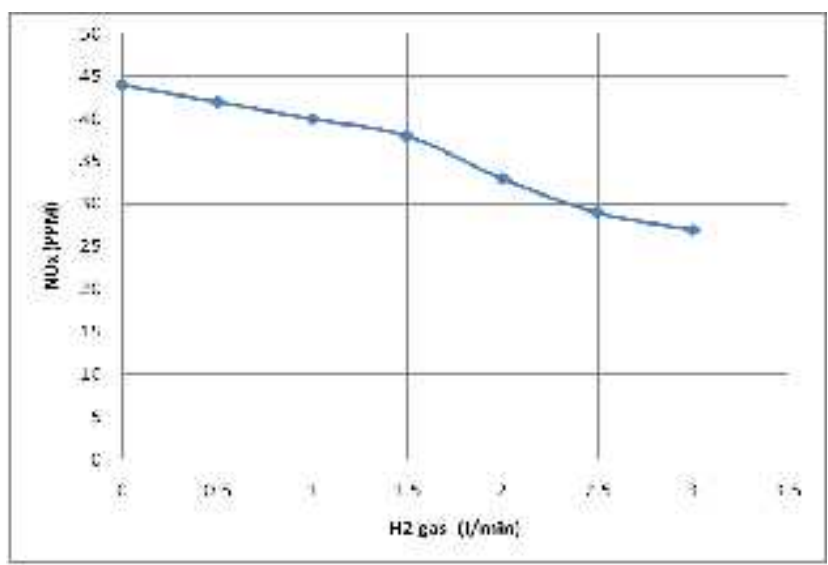

Fig. 4. Variation of NOx with HHO flow rate.

All three reactions are reversible. Zeldovich was the first to suggest the importance of the first two reactions. The last reaction of atomic nitrogen with the hydroxyl radical, $\mathrm{OH}$, was added by Heywood [4] to the mechanism and makes a significant contribution to the formation of thermal NOx.
This reduction in NOx emissions is due to hydrocarbons decomposition into $\mathrm{CH}$ radicals, which react with Nitrogen in the air to form $\mathrm{HCN}$ in the fuel-rich zone of the flame (Shudo) [5]. The maximum obtained reduction in NOx was within the range of 42 to 27 PPM when introducing 3 LPM of HHO gas. This is in agreement with Naha et al. [6] have demonstrated by numerical studies of chemical kinetic that NOx emissions decrease when HHO is injected; by using Chemkin package, they showed that the prompt NO decreases with hydrogen injection.

\subsubsection{Emission of $\mathrm{CO}_{2}$ and $\mathrm{CO}$ :}

A considerable decrease in the air-free $\mathrm{CO}$ emissions with hydrogen addition was noticed. This is in agreement with the results obtained by Lee et al [7]. This behavior was attributed with an increase in the $\mathrm{OH}$ radical which promotes the $\mathrm{CO}$ oxidation to $\mathrm{CO}_{2}$. Therefore, hydrogen is considered to be an appropriate choice for reducing this type of toxic emissions and increasing combustion efficiency [8]. From figure 5 it is noted that there are a decrease in $\mathrm{CO}_{2}$ emission about $20 \%$.

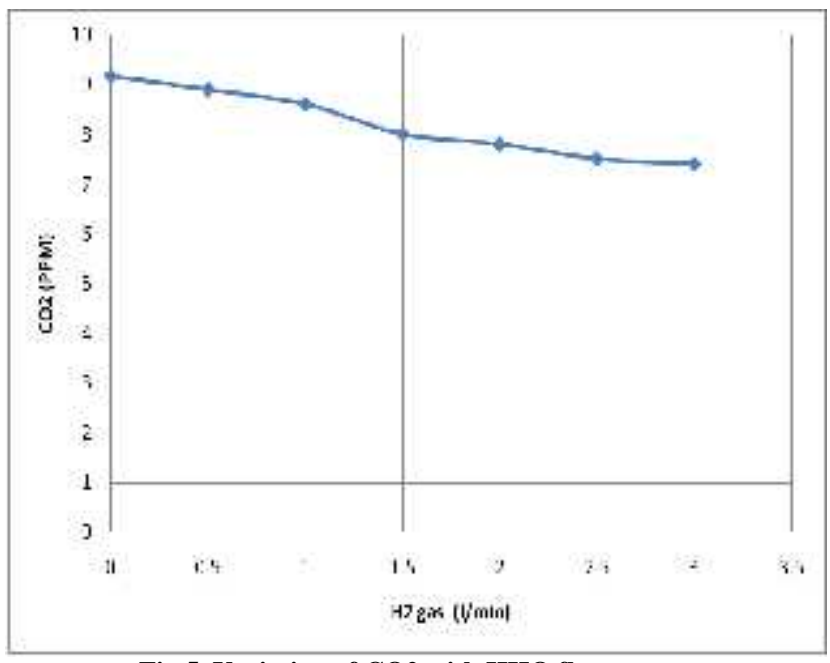

Fig.5. Variation of $\mathrm{CO} 2$ with $\mathrm{HHO}$ flow rate.

Figure 6 shows the obtained reduction in $\mathrm{CO}$ at different amounts of $\mathrm{H}_{2}$. $\mathrm{OH}$ radicals are important to flame stability because of their role in the chain branching reaction $\mathrm{H}+\mathrm{O}_{2} \leftrightarrow$ $\mathrm{OH}+\mathrm{O}$. Furthermore, the reduction in $\mathrm{CO}$ emissions with hydrogen addition was attributed with the increased radical pool. Higher $\mathrm{OH}$ concentrations are likely to promote completion of $\mathrm{CO}$ oxidation to $\mathrm{CO}_{2}$ via the $\mathrm{OH}$ radical [9].

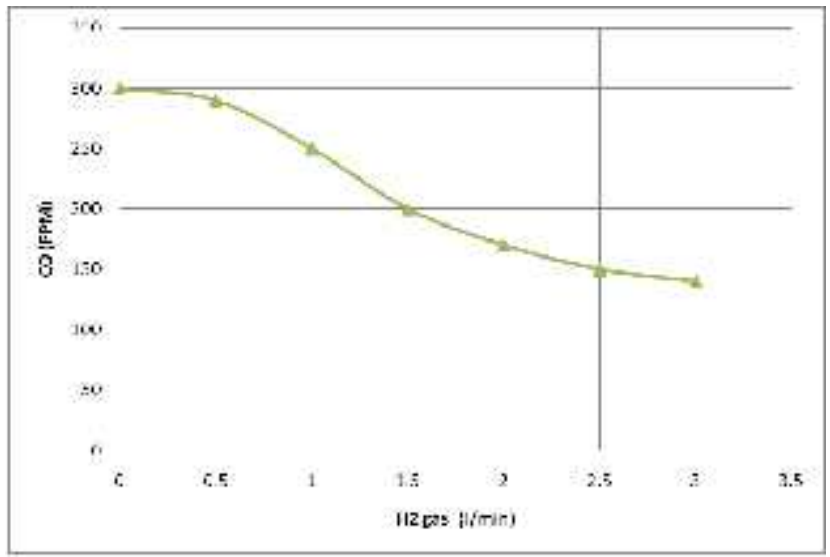

Fig.6. Variation of $\mathrm{CO}$ with $\mathrm{HHO}$ flow rate. 


\subsubsection{Emission of Sulfur dioxide $\left(\mathrm{SO}_{2}\right)$ :}

Figure 7 shows the effect of HHO addition on the emission of Sulfur dioxide during the combustion process as indicated in the figure the emission of $\mathrm{SO}_{2}$ with $\mathrm{HHO}$ added this is due to the fact that $\mathrm{HHO}$ - diesel mixture contains less count of sulfur to pure diesel. The maximum obtained reduction in $\mathrm{SO}_{2}$ emissions was within the range of 260 to 160 PPM at 3 LPM $\mathrm{H}_{2}$ flow rate.

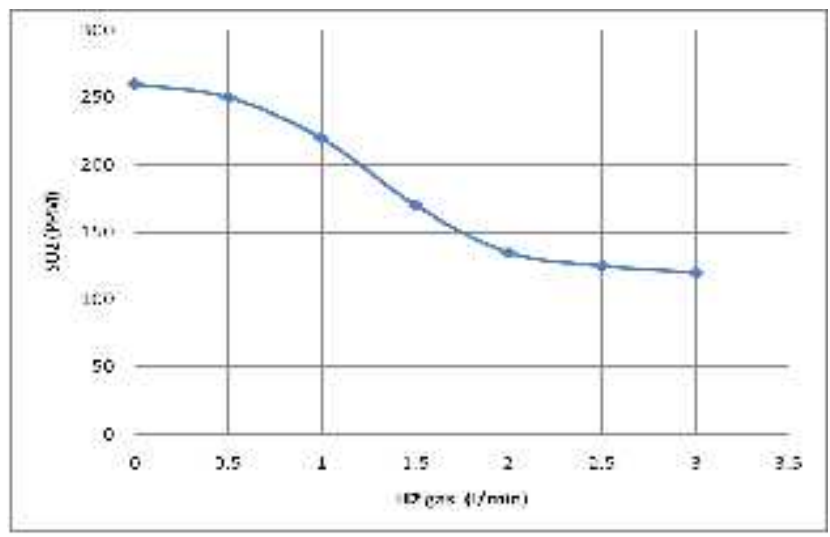

Fig.7. Variation of $\mathrm{SO}_{2}$ with $\mathrm{HHO}$ flow rate

\subsection{Effect on the exhaust gasses temperature:}

Figure 8 shows slight decrees in flue gas temperature due to the addition of HHO. This is attributed to the fact that when Hydrogen is burned; it forms vapor $\mathrm{H}_{2} \mathrm{O}$ as a result, which leads to lowering the exhaust gasses temperature.

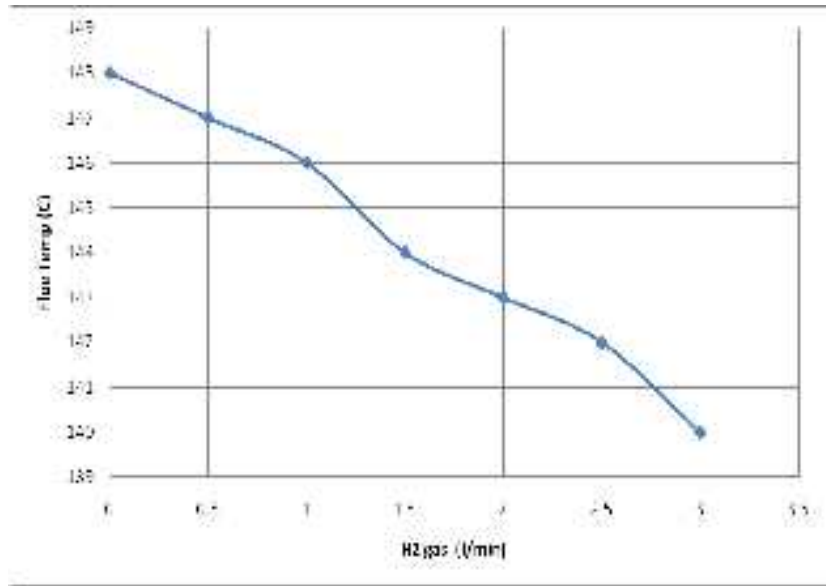

Fig.8. Variation of flue temperature with HHO flow rate.

\section{Conclusion}

From this work, the following may be concluded:

1. The idea to add brown gas to diesel in a regular boiler used in domestic heating was found to be a reasonable idea. The system was built and tested.

2. Combustion and thermal efficiencies increase with the amount of Brown gas added to diesel fuel.

3. The concentration of $\mathrm{CO}, \mathrm{NOx}$, and $\mathrm{SO}_{2}$ in the exhaust emission decreases with the quantity of the Brown gas added to Diesel fuel.

\section{Acknowledgments}

This is to acknowledgments the financial support provided by Al- Zaytoonah University of Jordan to conduct this research work.

\section{References}

[1] Yull Brown. US patent number 4,014,777 issued on March 29,1977 , and US patent number 4,081,656 issued on March 28, 1978.

[2] Fontana A, Galloni E, Jannelli E, Minutillo M. (2002) "Performance and fuel consumption estimation of a Hydrogen enriched gasoline engine at part-load operation". Soc Automot Eng, SAE paper no. 2002-012196.

[3] Whiete CM, Steeper RR, Lutz AE. (2006)“The Hydrogenfueled internal combustion engine: a technical review". Int J Hydrogen Energy;31:1292-305.

[4] John B. Heywood (1988) "Internal Combustion Engine Fundamentals". P 915. 3

[5] Shudo T, Mizuide T. (2002). "NOx emission characteristics in rich -lean combustion of Hydrogen". JSAE Rev

[6] Naha S, Aggarwal SK. (2004). "Fuel effects on NOx emissions in partially premixed flames. Combustion and Flame";139: 90-105.

[7] Jou C., Lee, C., Tsai C., and Wang, P. , Lin M. (2007) "Enhancing the performance of a high-pressure cogeneration boiler with waste Hydrogen-rich fuel". International Journal of Hydrogen Energy,33,5806-5810. 3

[8] Phillips N, and Roby, R (1999).”Enhanced Gas Turbine Combustor Performance Using H2-EnrichedNatural Gas". ASME Paper 99-GT-115.

[9] Schefer W, (2001)." Combustion of Hydrogen-Enriched Methane in a Lean Premixed Swirl Burner". Sandia National Laboratories 